\title{
Image Guided percutaneous pigtail catheter drainage of Liver Abscess technique and its outcome
}

\author{
Bhavika Jain ${ }^{1}$, Nikita Mantriं ${ }^{2}$, Rishika Saraf ${ }^{3}$, Shivaji Pole ${ }^{4}$, Devidas Baburao Dahiphale ${ }^{5}$, \\ Amol Lahoti ${ }^{6}$ \\ 1,2,3 Junior Resident, ${ }^{4}$ Associate Professor, ${ }^{5}$ Professor and Head, Department of Radiology, MGM Medical College and \\ Hospital, Aurangabad, ${ }^{6}$ Consultant Interventional Radiologist
}

Background: Liver abscesses are localized collections of necrotic inflammatory tissue caused by bacterial, parasitic or fungal agents. These abscesses are usually suspected clinically in cases having fever and tender hepatomegaly. The diagnosis is usually confirmed on the basis of imaging such as ultrasound and computerised tomography. Management includes antimicrobial agents and drainage of abscess. Percutaneous drainage of abscess is done using needle aspiration or catheter drainage. Aims and Objective: The main aim of the study was to evaluate the role of pigtail catheterization drainage procedure as a treatment option in cases of liver abscess. Materials and Methods: It was a prospective study conducted ata tertiary care medical college. Fifty patients having hepatic abscess were included in this study over a period of one year from August 2018 to September 2019 on the basis of a predefined inclusion and exclusion criteria. These patients underwent pigtail catheterization of liver abscess as a treatment. The demographic characteristics, hepatic lobe involvement, offending organisms and complications were studies in these patients. Results: Out of 50 patients 35 were male and 15 were femalewith a $M: F$ ratio of $1: 0.42$. The age ranged from 4 years to 92 years. The mean age of the studied cases was found to be $38.64+/-18.17$ years. Right lobe was involved in predominant cases. most common individual organism involved in hepatic abscess formation was klebsiella (30\%) followed by streptococcus (20\%) and E-coli ( $8 \%)$ organisms. Seven patients developed procedure related complications out of which 5 patients had catheter dislodgment requiring repositioning of catheter 1 patient developed pus discharge from catheter site and remaining 1 patient developed subcapsular hematoma. Conclusion: Percutaneous image guided pigtail catheter of liver abscess is an effective minimal procedure as a treatment option for liver abscess with high success rate with no mortality related to procedure.

Keywords: Hepatic Abscess; Ultrasonography; Pig Tail catheter; Percutaneous drainage
Access this article online

\section{Website:}

http://nepjol.info/index.php/AJMS DOI: $10.3126 /$ ajms.v12i7.34897

E-ISSN: 2091-0576

P-ISSN: 2467-9100

Copyright (c) 2021 Asian Journal of Medical Sciences

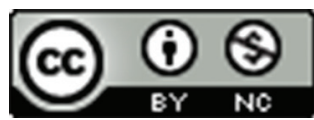

This work is licensed under a Creative Commons Attribution-NonCommercial 4.0 International License.

\section{INTRODUCTION}

Liver abscess is a localized collection of necrotic inflammatory tissue caused by bacterial, parasitic or fungal agents. It results from the invasion and multiplication of microorganisms, entering directly from an injury through the blood vessels or by the way of the biliary ductal system. ${ }^{1}$ In developed countries bacterial abscesses are more common and are usually seen in the setting of comorbidities. $^{2}$
Liver abscess occurs commonly in men and most commonly seen between 20 and 40 years of age. Approximately $60 \%$ of liver abscesses are solitary and mainly located in the right lobe of the liver. When multiple abscesses are present pyogenic or mixed is the most probable type. The presenting symptoms are right upper quadrant pain, fever and jaundice. Anorexia, malaise and weight loss can also be seen. ${ }^{3}$

The specific indications for intervention in these cases include for the purpose of differentiating pyogenic from 
amoebic abscess, cases in which there is severe pain pain, imminent rupture, poor response to medical therapy, falsenegative results of serologic tests, noncompliance with medical treatment, left lobe abscess and pregnancy. ${ }^{4}$ In majority of the cases catheter drainage may be curative and may expedite care for problematic amoebic liver abscesses in selected cases. ${ }^{5}$

Percutaneous drainage of liver abscess has become integral part in the treatment of pyogenic liver abscesses and has replaced the conventional surgical exploration. Percutaneous treatment includes needle aspiration or catheter drainage. Needle aspiration is less expensive, avoids problems related to catheter care and shortens duration of hospital stay. ${ }^{6}$ However, needle aspiration has lower success rate than catheter drainage as repeated needle aspirations is usually required in a single patient over a short period of time which is generally painful and unpleasant for the patients. To avoid these problems associated with needle aspiration, percutaneous pigtail catheter drainage is now used as the first tool in the management of liver abscesses. ${ }^{7}$

Liver abscess continues to be an important cause of morbidity and mortality, at least in the tropical countries. Early diagnosis and treatment have improved patients' outcome with the advent of newer modalities in the diagnosis \& treatment. ${ }^{8}$ The purpose of this study was to report and discuss our single large volume centre experience with US- or CT-guided percutaneous drainage of liver abscess, its course and importance of minimal invasive procedure with best practice protocols and results.

\section{MATERIALS AND METHODS}

This was a prospective study conducted in the department of radiology of MGM Medical College and Hospital, Aurangabad. The study period was of one year from august 2018 to September 2020. In this study all the patients (including paediatric age group) referred to us for imaging and in whom Image Guided percutaneous Pigtail Catheter drainage of Liver Abscess was done was included on the basis of a predefined inclusion and exclusion criteria. This study was pre-approved by the Institutional Ethical Committee.

Diagnosis of liver abscess was made from clinical history of the patient, physical examination followed by USG. CT scan was performed if required. An informed written consent was obtained from all the patients. Patients having rupture liver abscess into peritoneum or pleura, nonliquefied abscess and abnormal coagulation profile were excluded from the study.

\section{TECHNIQUE}

For pigtail drainage, 10 or 12 French pigtail catheter was selected according to viscosity of pus under USG guidance. Before procedure Inj. Atropine $0.5 \mathrm{mg}$ wasgiven intramuscularly. Painting, draping and isolation of the localized part was done. Under all aseptic precautions' drainage site was infiltrated with $2 \%$ lignocaine. Skin puncture was made at drainage site. Under real time sonographic guidance, the initial puncture needle (18G, 21 $\mathrm{cm}$ long) was inserted through the skin incision and guided to the centre of the abscess cavity.

The stellate was then taken out and pus was aspirated to confirm the position and the aspirated pus was sent to the laboratory for diagnostic purpose. A ' ' tip guide wire was inserted through the needle and the needle was taken out without displacing the guide wire. Serial dilators were passed keeping guide wire in situ and tract was dilated adequately if needed. Pigtail catheter was introduced and positioned into the cavity. Guide wire was withdrawn and pigtail was connected to a closed drainage bag and fixed to the skin through silk sutures. Alternate technique of combined Trocar-cannulacatheter assembly was inserted under Image guidance and inner stellate was removed to confirm drainage of pus (which was then sent for antimicrobial culture and sensitivity) and then catheter was placed inside the abscesses cavity. Subsequent to proper catheter placement sutures were taken and sterile dressing was done. The output was monitored immediately after the catheter placement and then daily. Antibiotics were started empirically initially and then were switched according to anti-microbial culture and sensitivity report. Alternate day ultrasound was done to monitor the cavity size, residual volume and to confirm the position of tip of the catheter. Clinical improvement in the patients' condition was noted in terms of relief from pain, fever, decreased WBC count and decrease in the volume of abscess cavity. In some cases, catheter position was adjusted according to output, catheter tip position and then again stay sutures were taken. The pigtail catheter was removed when USG was suggestive of reduced size or collapsed cavity without any residual pus. On removal of the catheter, sterile dressings were applied with betadine ointment pushed inside the tract to prevent tract infection, pus collection. All patients were advised for follow up clinically and on the basis of imaging to look for residual cavity and recurrence or non-resolving abscess. Clinical Improvement in the studied cases was analysed. For statistical purposes SSPS 21.0 software was used.

\section{RESULT}

In this study 50 patients underwent USG guided pigtail catheterization for liver abscess. Out of these 50 patients 
35 patients were males and 15 patients were female with a M: F ratio of 1:0.42 ( Figure 1).

The analysis of age distribution of the studied cases showed that the most common affected age group was $31-40$ years $(26 \%)$ followed by $41-50$ years $(24 \%)$ (Table 1$)$. Very few cases $(4 \%)$ were seen above the age of 70 years. The mean age of the studied cases was found to be 38.64 $+/-18.17$ years.

The analysis of cases on the basis of clinical presentation showed that in all cases $(100 \%)$ fever and abdominal pain was present. The other common complaints seen in these patients included Chills and rigors (84\%), Nausea or vomiting $(24 \%)$ followed by weight loss $(16 \%)$ and diarrhea $(14 \%)$ ( Figure 2).

The analysis of involved hepatic area showed that in majority of the patients $(84 \%)$ right lobe of liver was involved whereas in remaining $8(16 \%)$ patients left lobe of liver was involved (Table 2).

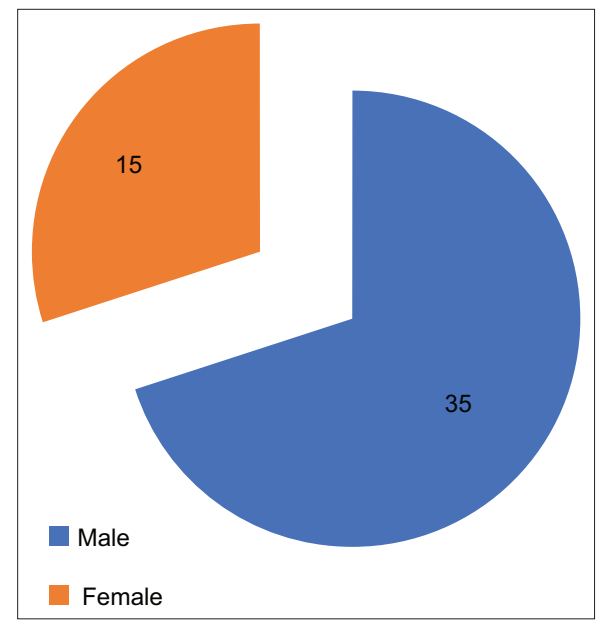

Figure 1: Gender Distribution of the studied cases
In $46(92 \%)$ cases solitary abscess was seen where as in remaining $4(8 \%)$ cases multiple abscesses were seen on ultrasound (Table 3).

Among 50 patients, 37 patients had volume more than $100 \mathrm{cc}$ and 13 patients $(26 \%)$ had less than or equal to $100 \mathrm{cc}$ of liver abscess (Table 4).

\begin{tabular}{lcc}
\multicolumn{2}{l}{ Table 1: Age distribution of the studied cases } \\
\hline Age distribution & \multicolumn{2}{c}{ Patients } \\
\cline { 2 - 3 } & Number of cases & Percentage \\
\hline $0-10$ & 4 & $8 \%$ \\
$10-20$ & 3 & $6 \%$ \\
$21-30$ & 5 & $10 \%$ \\
$31-40$ & 13 & $26 \%$ \\
$41-50$ & 12 & $24 \%$ \\
$51-60$ & 7 & $14 \%$ \\
$61-70$ & 4 & $8 \%$ \\
$71-80$ & 1 & $2 \%$ \\
$81-90$ & 0 & $0 \%$ \\
$91-100$ & 1 & $2 \%$ \\
\hline
\end{tabular}

\begin{tabular}{lcc}
\multicolumn{3}{l}{ Table 2: Lobe involvement } \\
\hline Lobe of liver involved & No of patients & Percentage \\
\hline Right lobe & 42 & $84 \%$ \\
Left lobe & 8 & $16 \%$ \\
\hline
\end{tabular}

\begin{tabular}{lcc} 
Table 3: Single Vs Multiple Abscesses \\
\hline Single Vs Multiple Abscesses & No of patients & Percentage \\
\hline Single Abscess & 46 & $92 \%$ \\
Multiple Abscesses & 4 & $8 \%$ \\
\hline
\end{tabular}

\begin{tabular}{lcc}
\multicolumn{3}{l}{ Table 4: volume of abscess } \\
\hline Volume of abscess & No of patients & Percentage \\
\hline$<100 \mathrm{cc}$ & 13 & $26 \%$ \\
$>100 \mathrm{cc}$ & 37 & $74 \%$ \\
\hline
\end{tabular}

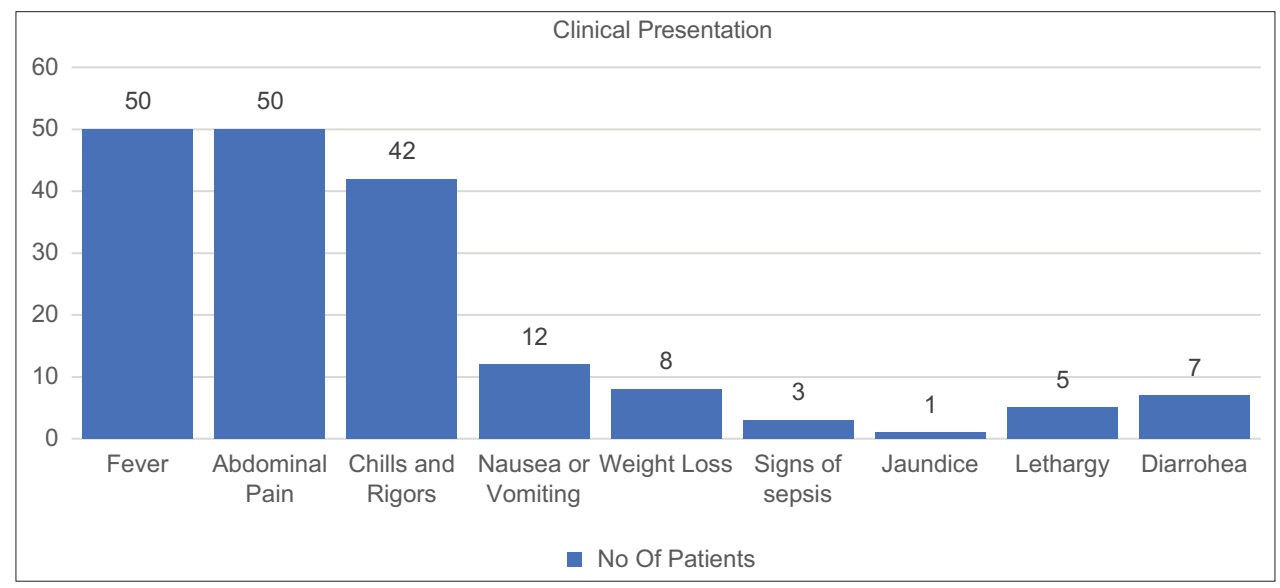

Figure 2: Presenting Complaints in the studied cases 
The analysis of microbiological data showed that the most common individual organism involved in hepatic abscess formation was klebsiella (30\%) followed by streptococcus $(20 \%)$ and E-coli (8\%) organisms. In $13(26 \%)$ cases polymicrobial growth was seen. In $5(10 \%)$ cases no growth was documented. IN $3(6 \%)$ cases E. Histolytica was isolated from pus (Figure 3).

Out of 50 patients, only 5 patients $(10 \%)$ required repositioning of the catheter (Table 5). Rest did not require any re-intervention procedure.

In number of days of pigtail catheter in situ, the range of days stayed from 0-15 days for 18 patients, 15-30 days for 27 patients and 30-45 days for 5 patients (Table 6). Average days being 18-21 days.

The analysis of cases on the basis of complications showed that in patients who had undergone Pigtail Catheter drainage of Liver abscess there were no procedure-related complications in 43 cases $(86 \%)$ and the procedure was uneventful. Out of remaining 7 patients 5 patients had catheter dislodgment requiring repositioning of catheter 1 patient developed pus discharge from catheter site and remaining 1 patient developed subcapsular hematoma (Figure 4). There was no mortality in any of the studied cases.

\section{DISCUSSION}

It was as early as in $400 \mathrm{BC}$ that Hippocrates described liver abscess and went on speculating that the prognoses of the patients were related to the type of fluid within the abscess cavity. ${ }^{9}$ The etiology of liver abscess is infection of liver through portal vein blood, retrograde infection through biliary, systemic, blood infection and other unknown occult infection. As of now liver abscess, both amoebic and pyogenic is a major tropical disease of the gastrointestinal system. Pyogenic liver abscess is noted more frequently in U.S whereas, amoebic liver abscess is commonly seen in tropic countries like India. ${ }^{10}$

Intravenous use of antibiotics is considered as one of the most important component of therapy for hepatic abscess. Use of antibiotics is mostly effective in controlling symptoms of patients with small liver abscess. However, for large liver abscess, single use of antibiotics is insufficient due to higher bacterial load, inadequate penetration of antibiotics and ineffective medium for bacterial elimination. ${ }^{11}$ Effective drainage is recognized as the most effective treatment for large liver abscess, since it could definitely lower bacterial burden and increase antibiotics penetration into the liver abscess. ${ }^{12}$ Percutaneous drainage

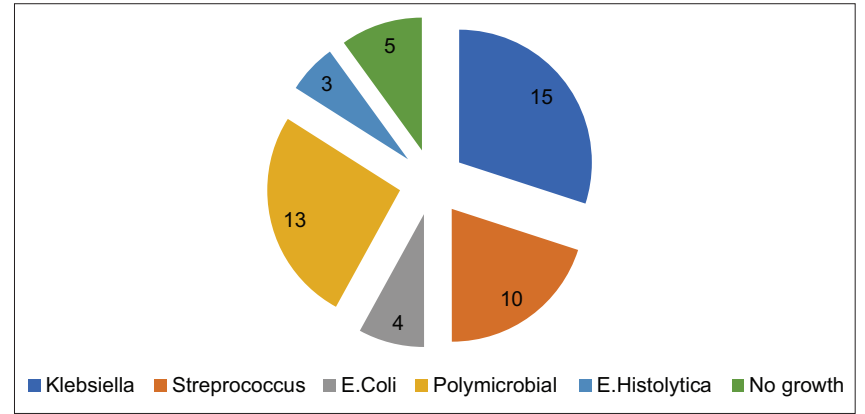

Figure 3: Micro-organisms isolated from pus

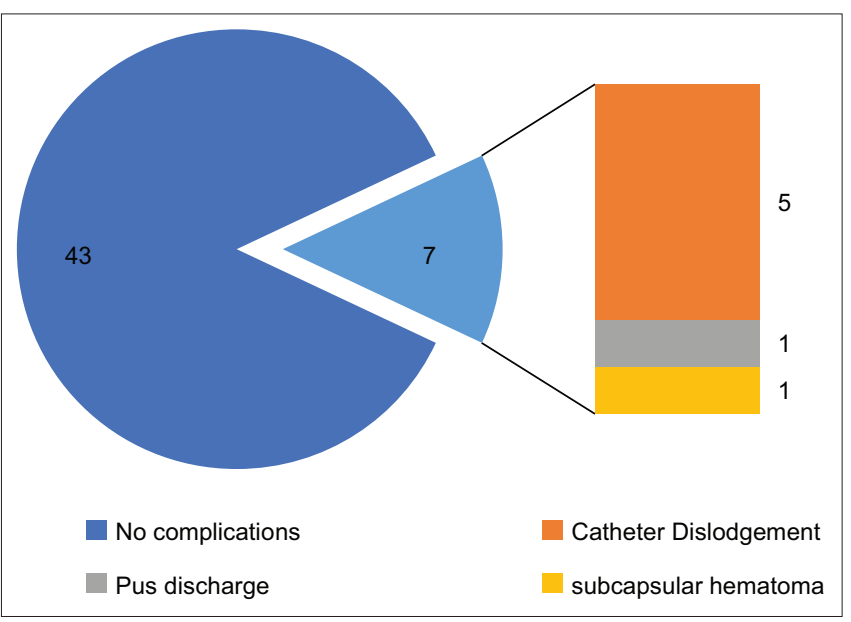

Figure 4 : Procedure Related compliocations in Studied cases

\begin{tabular}{lc} 
Table 5: repositioning of catheter \\
\hline Repositioning of catheter & No of patients \\
\hline Yes & 5 \\
No & 45 \\
\hline
\end{tabular}

\begin{tabular}{lc}
$\begin{array}{l}\text { Table 6: total number of days of pigtail } \\
\text { catheterization }\end{array}$ \\
\hline No of days pigtail catheter in-situ & No of patients \\
\hline $0-15$ & 18 \\
$15-30$ & 27 \\
$30-45$ & 5 \\
\hline
\end{tabular}

(PD) and surgical incision \&drainage (SD) are mainstays of liver abscess drainage. However, there was much debate on the abscess size and choice of drainage procedures. Many surgeons advocated use of PD in abscess around $3-6 \mathrm{~cm}$, and $\mathrm{SD}$ in abscess with larger size for complete drainage. ${ }^{13}$

With surfacing of antibiotics and imaging modalities, the management of liver abscess has changed with significant reduction in mortality and morbidity. Percutaneous drainage (including needle aspiration and catheter drainage) and surgical drainage are two alternative methods for drainage of pus from a large liver abscess. Due to minimal injury, accurate drainage, and rapid recovery of patients, 
PD has become the uppermost remedy of liver abscess. Percutaneous therapeutic procedures have been increasingly performed compared with open surgical drainage.Thisis because percutaneous drainage is less invasive procedure, less hospital stay. ${ }^{14}$

The present study evaluated the role of USG guided percutaneous pig tail catheter drainage in the management of liver abscess in 50 patients over a period of 1 year duration. In our study it was seen that the abscesses had predilection for male population $(70 \%)$ with the mean age of distribution lying between 31-50 yrs. In our study, $84 \%$ of the abscesses were located in the right lobe of liver, similar to previous studies. ${ }^{15}$ As compared to other studies where the number of days the catheter placed was 7-14days. ${ }^{16}$ Our study showed increased day of catheterization i.e. average being 18-21 days. However, the success rate of pigtail catheterization as a treatment option for liver abscess was similar to that of other studies. There are three types of liver abscesses namely amoebic, Pyogenic and fungal. In present perspective study we found no positive case of fungal abscess.

The problem of failure of this procedure as reported by earlier studies has been due to the thick and viscid pus, which cannot be easily drained by percutaneous drainage or early premature withdrawal of the catheter. ${ }^{17}$ Catheter adjustment is done of incomplete removal with imaging finding suggestive of residual collection to either exchange with wide bore catheter or do repositioning under USG or CT guidance to optimise catheter drainage. Catheter adjustments were needed for patients with large abscesses or accidental pulling of catheters. These problems can be avoided by using adequate sized pigtail catheters depending on the viscosity of pus, better stay sutures and following a strict protocol for catheter flushing and removal. Flush aspiration of the catheter is important either with Normal saline or antibiotic like metronidazole. $^{18}$

Percutaneous drainage has been accepted as the preferred method of treatment for collection- abscesses, as it is better tolerated by patients, eliminates the need for general anaesthesia, and is associated with shorter hospital stay periods. Mortality-morbidity rate after surgical drainage of liver abscesses is more than percutaneous drainage. ${ }^{19} \mathrm{In}$ our series none of the patient had mortality due related to procedure or multi-organ failure-Septicaemia. Percutaneous catheter drainage is relatively very safe procedure with few reported complications, which includes haemorrhage, perforation of hollow viscera, peritoneal spillage, catheter displacement or blockage and septicaemia. ${ }^{20}$ But recent studies show very low complication rates. Our study did not have any major complication although the incidence of minor complications was present but very less. Possible failure reasons of percutaneous abscess drainage are clinical misdiagnosis of a tumour as an abscess, wrong drainage technique

\section{CONCLUSION}

Liver abscess used to be associated with high morbidity and mortality requiring open surgical drainage (SD) in earlier days. But with invent of interventional procedures namely percutaneous imagedrainage (PD) procedures under ultrasound or CT guidance, the outcome has improved significantly. Hepatic abscess, percutaneous drainage may achieve the same curative ratio as surgical drainage and have an advantage of being less invasive and less painful procedure. Moreover, it is associated with lower morbidity and shorter hospital stay. Therefore, percutaneous drainage should be done in all hepatic abscesses whenever feasible. Percutaneous drainage in combination with targeted antimicrobial therapy has almost become gold standard in management of liver abscess management. From this study, it is concluded that image guided percutaneous pigtail drainage of liver abscess is a very safe, effective minimally invasive procedure with negligible morbidity and no mortality.

\section{REFERENCES}

1. Italiya $H B$, Shah PR, Rajyaguru AM and Bhatt JG. A prospective study of USG guided pigtail catheter drainage in management of liver abscess. Int J Res Med Sci. 2015;3(3):574-578.

https://doi.org/10.5455/2320-6012.ijrms20150308

2. Zhang J, Du Z, Bi J, Wu Z, Ly Y, Zhang X, et al. Comparison of clinical characteristics and outcomes of pyogenic liver abscess patients $<65$ years of age versus $\geq 65$ years of age. BMC Infect Dis. 2019;19(1):233.

https://doi.org/10.1186/s12879-019-3837-2

3. Abbas MT, Khan FY, Muhsin SA, Al-Dehwe B, Abukamar M and Elzouki AN. Epidemiology, Clinical Features and Outcome of Liver Abscess: A single Reference Center Experience in Qatar. Oman Med J. 2014; 29(4):260-263.

https://doi.org/10.5001/omj.2014.69

4. Aydin C, Piskin T, Sumer F, Barut B and Kayaalp C. Laparoscopic drainage of pyogenic liver abscess. JSLS. 2010;14(3):418-420. https://doi.org/10.4293/108680810X12924466006567

5. Wuerz T, Kane JB, Boggild AK, Krajden S, Keystone JS, Fuksa M, et al. A review of amoebic liver abscess for clinicians in a nonendemic setting. Can J Gastroenterol. 2012; 26(10):729-733. https://doi.org/10.1155/2012/852835

6. Rajak CL, Gupta S, Jain S, Chawla Y, Gulati M and Suri S. Percutaneous treatment of liver abscesses: needle aspiration versus catheter drainage. AJR Am J Roentgenol. 1998;170(4):1035-1039.

https://doi.org/10.2214/ajr.170.4.9530055

7. Wong KP. Percutaneous drainage of pyogenic liver abscess. World J Surg. 1990; 14:492-497. 4. 
https://doi.org/10.1007/BF01658674

8. Townsend CM, Beauchamp RD, Evers BM, Mottox KI, eds Sabiston Text Book of Surgery. 17th ed. USA: Elsevier; 2004: 1534-1542.

9. Hippocrates. The Genuine Works of Hippocrates, vols 1 \& 2. Trans [from the Greek with a preliminary discourse and annotations]. New York: William Wood \& Co. 1886:57,58,266,267.

10. Cook GC. Gastroenterological emergencies in the tropics. Baillieres Clin Gastroenterol. 1991; 5:861- 886. https://doi.org/10.1016/0950-3528(91)90024-U

11. Serraino C, Elia C, Bracco C, Rinaldi G, Pomero F, Silvestri A, et al. Characteristics and management of pyogenic liver abscess: A European experience. Medicine (Baltimore). 2018;97(19): e0628.

https://doi.org/10.1097/MD.0000000000010628

12. Pang TC, Fung T, Samra J, Hugh T J and Smith RC. Pyogenic liver abscess: an audit of 10 years' experience. World J Gastroenterol.2011; 17: 1622-1630.

https://doi.org/10.3748/wjg.v17.i12.1622

13. Tan YM, Chung AY, Chow PK, Cheow PC, Wong WK, Ooi LL, et al. An appraisal of surgical and percutaneous drainage for pyogenic liver abscesses larger than $5 \mathrm{~cm}$. Ann Surg. 2005;241(3):485-490 https://doi.org/10.1097/01.sla.0000154265.14006.47

14. Malik AA, Bari SU, Rouf KA and Wani KA. Pyogenic liver abscess: Changing patterns in approach. World J Gastrointest Surg. 2010;2(12):395-401.

https://doi.org/10.4240/wjgs.v2.i12.395
15. Malik SM, Bhasin SK and Azad TP. Outcome of ultrasound guided pigtail catheter drainage of liver abscesses a prospective study of 126 cases. Int Surg J. 2015;2(4):634-640. https://doi.org/10.18203/2349-2902.isj20151093

16. Gupta AK, Kumar $Y$ and Soni A. A clinical study on the presentation and management of liver abscess in eastern Uttar Pradesh and evaluation of a low-cost technique of percutaneous catheter drainage. Int Surg J. 2019; 6(4):1238-1241. https://doi.org/10.18203/2349-2902.isj20191255

17. Lai KC, Cheng KS, Jeng LB, Huang CC, Lee YT, Chang HR, et al. Factors associated with treatment failure of percutaneous catheter drainage for pyogenic liver abscess in patients with hepatobiliary-pancreatic cancer. Am J Surg. 2013; 205(1):52-57. https://doi.org/10.1016/j.amjsurg.2012.03.006

18. Liao WI, Tsai SH, Yu CY, Huang GS, Lin YY, Hsu CW, et al. Pyogenic liver abscess treated by percutaneous catheter drainage: MDCT measurement for treatment outcome. Eur $\mathrm{J}$ Radiol. 2012; 81(4):609-615. https://doi.org/10.1016/j.ejrad.2011.01.036

19. Tu JF, Huang XF, Hu RY, You HY, Zheng XF and Jiang FZ. Comparison of laparoscopic and open surgery for pyogenic liver abscess with biliary pathology. World J Gastroenterol. 2011;17(38):4339-4343. https://doi.org/10.3748/wjg.v17.i38.4339

20. Sharma N, Kaur H, Kalra N, Bhalla A, Kumar S and Singh V. Complications of Catheter Drainage for Amoebic Liver Abscess. J Clin Exp Hepatol. 2015; 5(3):256-258. https://doi.org/10.1016/j.jceh.2015.06.003

\section{Author's contribution:}

BJ-Concept and design of the study; interpreted the results, prepared first draft of manuscript and critical revision of the manuscript; NM and RS-Statistically analyzed and interpreted; reviewed the literature and manuscript preparation; SP and DD- Design of the study, statistically analyzed and interpreted, preparation of manuscript and revision of the manuscript; AL- Concept and coordination of the overall study.

\section{Work Attributed to}

Department of Radiology, MGM Medical College, Aurangabad.

\section{ORCID ID:}

Dr. Bhavika Jain- (i) https://orcid.org/0000-0002-6898-6246

Dr. Nikita Mantri- (1) https://orcid.org/0000-0001-7522-2271

Dr. Rishika Saraf- (1) https://orcid.org/0000-0001-6937-587X 